\title{
FORMULAS AND TABLES FOR THE CALCULATION OF THE INDUCTANCE OF COILS OF POLYGONAL FORM.
}

\author{
By Frederick W. Grover.
}

\begin{abstract}
.
Coils wound on forms such that each turn incloses a regular polygon are finding frequent use in radio circuits. Not only are they easy to construct, but support for the wires of the coil is necessary only at the vertices of the polygon. Thus, the amount of dielectric near the wires is small, making it easy to reduce energy losses in the dielectric to a very small amount.

In this paper formulas are derived for the calculation of the inductance of such coils. The cases treated are triangular, square, hexagonal, and octagonal coils. It is found that a circular coil inclosing the same area as the polygonal coil, the length and the number of turns being the same in both cases, has nearly the same inductance as the polygonal coil.

This suggests the presentation of the results in such a way as to enable the radius of the circular coil having the same inductance as the given polygonal coil to be found. Knowing this, the inductance of the polygonal coil can be found by existing formulas and tables applicable to circular coils.

The tables here given show what is the equivalent radius of the polygonal coils which are likely to be met in practice. Other cases can be treated by a simple interpolation.
\end{abstract}

\section{CONTENTS.}

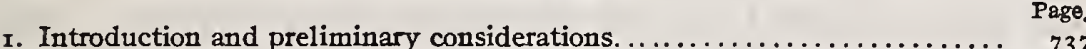

2. Method of solution. .........................................

3. Single-layer coil of square section, square solenoid................... 74 I

4. Simplified method for other polygons........................ 743

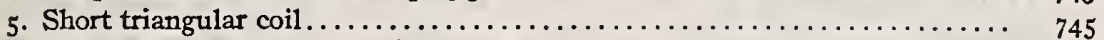

6. Hexagonal coil........................................ $7_{44}$

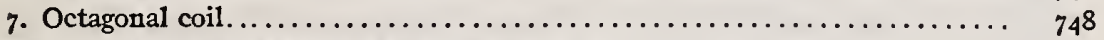

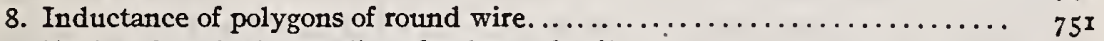

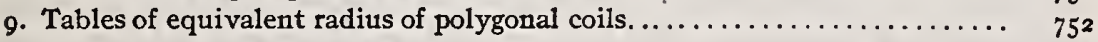

Io. Correction for insulation space.............................. 755

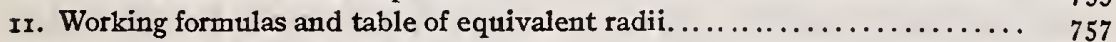

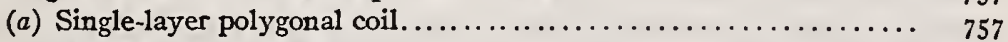

(b) Multiple-layer polygonal coil ......................... $75^{8}$

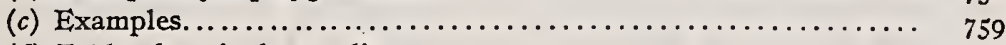

(d) Table of equivalent radius........................ 761

1. INTRODUCTION AND PRELIMINARY CONSIDERATIONS.

Single-layer coils find very common use in radio circuits on account of the simplicity of their construction and their small capacity. However, the presence of insulating material in con- 
tact with the wire, or close to it, is objectionable on account of the danger of appreciable power loss in the insulating material which is often a far from perfect dielectric. This difficulty is avoided if the wire be wrapped around frames of such a shape that each turn incloses a polygon, instead of a circle, as in the usual helical coil. With such a construction the wire is in contact with the insulating material, or near it, only at the vertices of the polygon. This form of winding may be extended to multilayer coils by inserting small pieces of thin dielectric between successive layers of the winding at the vertices of the polygon.

Such coils possess as small a capacity as the corresponding coils of circular turns with the added advantage of elimination of energy losses in dielectric material, and have found an extensive use in recent years. At the Bureau of Standards a set of single-layer coils wound on bakelite forms of such a shape that each turn has the shape of a 12-sided polygon has been used as standards of inductance in radio measuring circuits. It is, accordingly, a matter of importance to be able to calculate accurately the inductance of coils of this type from their dimensions. Other cases frequently arise where a calculation of the inductance is required for a coil of polygonal shape, such as, for example, the calculation of the leakage reactance of the coils of certain forms of core-type transformer.

The present paper has for its object not only the derivation of formulas for the calculation of the inductance of polygonal coils, but also to furnish tables for simplifying the calculations. These should prove useful for the case of both single-layer and multilayer coils, as will be shown below.

At the beginning of this work the author was cognizant of no published work bearing on this problem, but after the completion of the mathematical work of the paper, his attention was called to a valuable article by Niwa, ${ }^{1}$ in which is studied the magnetic field of a square solenoid or single-layer coil whose turns inclose a square area. Niwa has derived a formula for the inductance of such a solenoid which can be shown to be equivalent to the independently derived formula given as equation (3) below. A table given by Niwa for use with his formula has been found very useful in checking the numerical constants here given,

1 Yasujiro Niwa. "On the solenoid with rectangular cross section." Research Paper No. 73 of the Electrotechnical Laboratory of the Japanese Department of Communications. (Published in English.) Tokyo; November, 1918. 
although the plan of calculation here adopted differs from that of Niwa.

It is at once evident that in the limiting case of an extremely long polygonal coil the inductance must be equal to that of a circular solenoid of the same length, provided that the turns of the two coils inclose the same area. On the other hand, in the case of a single wire bent to form a polygon of large area, the magnetic field is strong only in the vicinity of the wire, so that the inductance is dependent on the length of the wire rather than on the area inclosed. In the limiting case, the equivalent circle of wire would be that of equal perimeter with the polygon. For convenience we may speak of the equivalent circular coils in the two cases as equal-perimeter coils and equal-area coils, the length and number of turns being supposed the same. The inductances of these two circular coils can be accurately calculated, and thus upper and lower limits, respectively, can be obtained between which the inductance of the actual polygonal coil must lie. It is obvious that the greater the number of sides of the polygon, the more closely these two limits approach one another. The measured values of the inductances of the Bureau of Standards r 2-sided coils, while on the whole pointing to the equal area assumption as the closer approximation of the two, were not sufficient to give a conclusive judgment on this point, since the errors of measurement in some cases were comparable with the difference between the two limiting inductances. This suggests that, where high accuracy is not required, it is sufficient to calculate these two limiting inductances. It will be shown later that the true inductance lies between these limits, but much nearer the lower than the upper limit.

Besides their usefulness in thus fixing an approximate value for the inductance, these considerations suggest, naturally, that the more accurate calculation of the inductance be put into the form of the calculation of the radius of a circular solenoid having the same inductance as the actual coil, the length and number of turns being assumed to be the same in both cases. This procedure has the great advantage that formulas and tables are already at hand for the very accurate calculation of the inductance of circular solenoids of any form whatever. In systematizing the calculation of the inductance of polygonal coils, then, the tables of this paper give the means of obtaining the equivalent radius of the circular solenoid of equal inductance, and the inductance of the coil is then calculated by the usual formula and table applicable to a 
circular solenoid. It is necessary, however, first to develop formulas for calculating the inductance of the polygonal coil, and, naturally, different formulas apply according to the number of sides of the polygon.

\section{METHOD OF SOLUTION.}

The most direct method of solution is to obtain a formula for the mutual inductance of two equal, parallel, coaxial polygons of the number of sides in question. On integrating this twice over the length of the coil an expression results which gives the inductance of a cylindrical current sheet having the given polygon as its base. This general expression may be compared with that for a circular cylindrical current sheet, and the radius of the equivalent circular cylinder giving the same inductance may be obtained. In an actual coil, of course, the current does not flow in a continuous sheet but is concentrated in wires. The difference in inductance of an actual coil and the equivalent current sheet found as described below is small and may be accurately taken into account as shown in section Io. By carrying out this determination for coils of different lengths, a table may be prepared from which the radius of the equivalent circular cylinder may be taken for any desired case. Of course, a different general formula must be derived for each different number of polygon sides. However, by making a study for a number of cases where the polygons have few sides, it is possible to approximate with sufficient closeness the values of the equivalent radius for polygons of a greater number of sides, since we know that the limits of variation of the equivalent radius are smaller the greater the number of sides.

The formula for the mutual inductance of two parallel squares is well known. The integration of this expression, although long and tedious, offers no especial difficulties. Having derived the general expression for the square solenoid, a study of the variation of the equivalent radius was made, and showed that the deviations from the radius of the equal-area circle are very small. Even for very short square coils the equivalent radius lies much closer to that of the equal-area circle than to that of the equal-perimeter circle. This is true even for a single turn of wire of moderate thickness bent into a square of, say, I foot on a side. This fact was also noted by Niwa.

The cases of triangular, hexagonal, and octagonal coils were also treated. Since the formulas for the mutual inductances of equal, parallel polygons of these numbers of sides were not available, they had to be derived. This was done by making use of 
a basic, general formula, due to Martens, ${ }^{2}$ which gives the mutual inductance of two straight filaments of any desired lengths, situated in any desired relative position. The resulting expressions are all exact, and in terms of elementary functions, but are long and cumbrous. To integrate these expressions would in every case be possible, but would be so arduous that it is very fortunate that a simplification of the process suffices to give the accuracy demanded in practice. This will be explained in a later section.

\section{SINGLE-LAYER COIL OF SQUARE SECTION, SQUARE SOLENOID.}

The formula for the mutual inductance of two equal, parallel, coaxial rectangles was first given by $\mathrm{F}$. E. Neumann in 1845 . For the special case of two squares it becomes

$$
\begin{aligned}
M= & 0.008\left[a \log \frac{\sqrt{a^{2}+d^{2}}}{d}+a \log \frac{a+\sqrt{a^{2}+d^{2}}}{a+\sqrt{2 a^{2}+d^{2}}}\right. \\
& \left.+\sqrt{2 a^{2}+d^{2}}-2 \sqrt{a^{2}+d^{2}}+d\right] \quad \text { microhenries }
\end{aligned}
$$

in which $a$ is the side of the square, and $d$ is the distances between their planes.

All logarithms here, and later, are Napierian unless otherwise stated. Lengths are in centimeters and inductances in microhenries throughout.

Integrating this expression over the length of the coil, there is obtained the mutual inductance between one square turn and the rest of the coil, and a second integration over the length of the coil gives the self-inductance of the square solenoid. The integration involves known integrals, or, at worst, integrals which may be evaluated by usual devices. The work is, however, long and tedious, and only the final result will be given. Placing $n$ equal to the number of turns, and $b$ for the length of the coil, the inductance is:

$$
\begin{aligned}
L=0.008 a n^{2}[ & \log \frac{a+\sqrt{a^{2}+b^{2}}}{a+\sqrt{2 a^{2}+b^{2}}}+\frac{a^{2}}{b^{2}} \log \frac{a+\sqrt{2 a^{2}+b^{2}}}{a+\sqrt{2 a^{2}}} \\
& +\frac{1}{2}\left(\mathrm{I}-\frac{a^{2}}{b^{2}}\right) \log \left(a^{2}+b^{2}\right)+\frac{a^{2}}{b^{2}} \log a-\log b \\
& -\frac{\pi a}{b}+2 \frac{a}{b} \sin ^{-1} \frac{2 a+\sqrt{2 a^{2}+b^{2}}}{\sqrt{2\left(a+\sqrt{2 a^{2}+b^{2}}\right)}}+2 \frac{a}{b} \tan ^{-1} \frac{b}{a} \\
& +\frac{a}{b^{2}} \sqrt{a^{2}+b^{2}}-\frac{a}{b^{2}} \sqrt{2 a^{2}+b^{2}}+\frac{1}{3}(\sqrt{2}-\mathrm{I}) \frac{a^{2}}{b^{2}} \\
& \left.+\frac{1}{3} \frac{\left(2 a^{2}+b^{2}\right)^{\frac{3}{2}}}{a b^{2}}-\frac{2}{3} \frac{\left(b^{2}+a^{2}\right)^{\frac{3}{2}}}{a b^{2}}+\frac{1}{3} \frac{b}{a}\right] \text { microhenties. }
\end{aligned}
$$

\footnotetext{
Ann. der Phys., 334, p. 963; rgog.
} 
A more symmetrical form of writing gives:

$$
\begin{aligned}
L=0.008 a n^{2} & {\left[\log \frac{\sqrt{a^{2}+b^{2}}}{b}-\log \frac{a+\sqrt{2 a^{2}+b^{2}}}{a+\sqrt{a^{2}+b^{2}}}+\frac{a^{2}}{b^{2}} \log \frac{a+\sqrt{2 a^{2}+b^{2}}}{a+\sqrt{2 a^{2}}}\right.} \\
& -\frac{a^{2}}{b^{2}} \log \frac{\sqrt{a^{2}+b^{2}}}{a}+\frac{2 a}{b} \tan ^{-1} \frac{b}{\sqrt{2 a^{2}+b^{2}}} \\
& +\frac{a}{b^{2}} \sqrt{a^{2}+b^{2}}-\frac{a}{b^{2}} \sqrt{2 a^{2}+b^{2}}+\frac{\mathrm{I}}{3}(\sqrt{2}-\mathrm{I}) \frac{a^{2}}{b^{2}} \\
& \left.+\frac{\mathrm{I}}{3} \frac{\left(2 a^{2}+b^{2}\right)^{\frac{3}{2}}}{a b^{2}}-\frac{2}{3} \frac{\left(a^{2}+b^{2}\right)^{\frac{3}{2}}}{a b^{2}}+\frac{\mathrm{I}}{3} \frac{b}{a}\right] \text { microhenries. }
\end{aligned}
$$

This expression was derived by the author in October, I9I 7. The formula published by Niwa in November, 1918, may be shown to be equivalent to formula (3), but it appears in a less simple form.

Like all formulas for the inductance of circuits composed of straight filaments, formula (3) is a closed expression, but in certain cases it is poorly adapted to numerical calculations. In such cases, series expansions give a satisfactory accuracy with very much less labor. Two series developments of formula (3) follow.

For short coils, where $\frac{b}{a}$ is small, there may be used the very convergent expression:

$$
\begin{aligned}
& L= 0.008 a n^{2} \\
& {\left[\log \frac{a}{b}+0.72599+\frac{\mathrm{I}}{3} \frac{b}{a}-\frac{(3-2 \sqrt{2})}{24} \frac{b^{2}}{a^{2}}-\frac{(6 \sqrt{2}-5)}{480} \frac{b^{4}}{a^{4}}\right.} \\
&\left.+\frac{(23 \sqrt{2}-14)}{5376} \frac{b^{6}}{a^{6}}-\frac{(37 \sqrt{2}-28)}{9^{216}} \frac{b^{8}}{a^{8}}+\cdots\right] \\
& L=0.008 a n^{2}\left[\log \frac{a}{b}+0.72599+\frac{1}{3} \frac{b}{a}-0.007149 \frac{b^{2}}{a^{2}}-0.00726 \mathrm{I} \frac{b^{4}}{a^{4}}\right. \\
&\left.+0.003446 \frac{b^{6}}{a^{6}}-0.002640 \frac{b^{8}}{a^{8}}+\cdots\right] \quad \text { microhenries, }
\end{aligned}
$$

and for long coils, where $\frac{a}{b}$ is small,

$$
\begin{gathered}
L=0.004 \frac{\pi a^{2} n^{2}}{b}\left[\mathrm{I}-\frac{2}{\pi}\left\{\log (\mathrm{I}+\sqrt{2})-\frac{(\sqrt{2}-\mathrm{I})}{3}\right\} \frac{a}{b}+\frac{\mathrm{I}}{2 \pi} \frac{a^{2}}{b^{2}}\right. \\
\left.-\frac{\mathrm{I}}{\mathrm{I} 2 \pi} \frac{a^{4}}{b^{4}}+\frac{\mathrm{I}}{28 \pi} \frac{a^{6}}{b^{6}}-\ldots\right] \\
\begin{aligned}
L=0.004 \frac{\pi a^{2} n^{2}}{b} & {\left[\mathrm{I}-0.473199 \frac{a}{b}+0.15916 \frac{a^{2}}{b^{2}}-0.02653 \frac{a^{4}}{b^{4}}\right.} \\
& \left.+0.01137 \frac{a^{\circ}}{b^{6}}-\ldots\right]
\end{aligned}
\end{gathered}
$$


This last expression was also found by Niwa (p. I 9 of his paper). Formula (5) is similar in form to the Webster-Havelock formula ${ }^{3}$ for the inductance of a long cylindrical current sheet, which with $R$ to denote the radius of the cylinder may be written

$$
L_{c}=0.004 \frac{\pi^{2} R^{2} n^{2}}{b}\left[\mathrm{I}-\frac{8}{3 \pi} \frac{R}{b}+\frac{\mathrm{I}}{2} \frac{R^{2}}{b^{2}} \div \frac{\mathrm{I}}{4} \frac{R^{4}}{b^{4}}+\cdots\right]
$$

Imposing the condition that the area of the square is the same as that of the circle; that is, $\pi R^{2}=a^{2}=A$, the formulas for the long, square coil and the long cylindrical coil may be written, respectively, as:

$$
\begin{aligned}
& L_{s}=0.004 \frac{\pi A n^{2}}{b}\left[\mathrm{I}-0.83872 \frac{R}{b}+\frac{\mathrm{I}}{2} \frac{R^{2}}{b^{2}}-0.2618 \frac{R^{4}}{b^{4}}+\cdots\right] \\
& L_{c}=0.004 \frac{\pi A n^{2}}{b}\left[\mathrm{I}-0.84882 \frac{R}{b}+\frac{\mathrm{I}}{2} \frac{R^{2}}{b^{2}}-\frac{\mathrm{I}}{4} \frac{R^{4}}{b^{4}}+\cdots\right]
\end{aligned}
$$

which show clearly that, for the same area inclosed by the turns (the number of turns and the lengths of the coils being the same) the long, square coil will have a slightly larger inductance than the circular coil. That is, for the same inductance the circular coil must have a slightly larger radius than corresponds to an area of section equal to that of the square. To a first approximation, the area of the circular coil must be increased in the ratio of the inductance of the square coil, as compared with that of the circular coil as derived from equations (7) and (8). This relation gives, however, only a first approximation, and accurate values have to be derived by a method of successive approximations (see sec. 9).

\section{SIMPLIFIED METHOD FOR OTHER POLYGONS.}

As has already been pointed out, the expressions for the mutual inductance of parallel polygons are long and cumbrous, and their integration to find the inductance of a polygonal coil is quite formidable. A considerable simplification is, however, afforded by the use of geometric and arithmetic mean distances. This method may, perhaps, be most readily illustrated by applying it to the case of the square coil; the fact that we have the solution for this case makes it possible to check the results.

8 Bull. Am. Math. Soc., 14, no. I, p. I; 1907. Phil. Mag., 15, p. 332; 1908. B. S. Sci. Papers, No. 169. D. I2I; I912 (B. S. Bulletin, 8, p. 121).

$11392^{\circ}-23-2$ 
The series formula (4) for the short square coil was derived by expanding the general solution (formula (2)). It may be equally well obtained by first expanding formula (I) for the mutual inductance of parallel squares in powers of $\frac{b}{a}$, and then by integrating this expression twice, term by term, over the length of the coil.

The expanded form of $(x)$ is readily found to be

$$
M=0.008 a\left[\log \frac{a}{d}-0.7740 \mathrm{I}+\frac{d}{a}-\frac{(3-2 \sqrt{2})}{4} \frac{d^{2}}{a^{2}}-\frac{(6 \sqrt{2}-5)}{32} \frac{d^{4}}{a^{4}}+\cdot \cdot\right] \text { (9) }
$$

Now the integration of the term $\log d$ is equivalent to finding the average value, $\log D$, of the logarithms of the distances between all the possible pairs of the points of the straight line of length $b$. The distance $D$ is called the geometric mean distance of the points of the line $b$ from one another. Its value is known to be

$$
\log D=\log b-\frac{3}{2}
$$

Likewise the integration of any of the other terms $d^{n}$ is equivalent to obtaining the average of the $n$th power of the distance between all the possible pairs of points of the line of length $b$. Thus for $d$ we obtain $\frac{b}{3}$; for $d^{2}, \frac{b^{2}}{6}$; for $d^{4}, \frac{b^{4}}{15}$; and, in general, for $d^{2 n}$ the value $\frac{b^{2 n}}{(2 n+1)(n+1)} \cdot$ Making these substitutions, equation (9) goes over immediately into equation (4). Thus we have avoided the integration by making use of results which have been obtained by carrying through the integrations once for all, in the past.

This method gives us, then, an abbreviated process for finding the inductance of a short polygonal coil. First, obtain the formula for the mutual inductance of the two equal, parallel, coaxial polygons; next, expand this in powers of the ratio of the distance between their planes and the side of the polygon; and finally, substitute in this series for $\log d, d, d^{2}$, etc., the known values of the geometric and arithmetic mean distances of the line having a length equal to the length of the coil, as shown above. This method can not be used for obtaining the inductance of a long polygonal coil, since in the integration for this case, the mutual 
inductance of both near and distant polygons is involved, and no series expansion can cover both cases. For short coils, however, the method is very valuable, not only because the integration does not have to be made, but because the result is obtained in a convenient series form without the necessity of making a further expansion. It must not be forgotten, however, that even this method requires that the formula for the mutual inductance of the parallel polygons be found, and then this must be expanded in series form, both processes being sufficiently arduous. As has been pointed out, for long coils the equivalent radius of the solenoid of equal inductance differs little from that of the equal-area solenoid, and it is found possible to interpolate with sufficient accuracy the small deviations from this. This point is discussed more fully in section 9 .

The following sections give the formulas resulting from the application of the abbreviated method to the cases of triangular, hexagonal, and octagonal coils.

\section{SHORT TRIANGULAR COIL.}

To obtain the formula for the mutual inductance of two equal, parallel, coaxial, equilateral triangles, Marten's general formula has to be adapted to the case of two straight filaments making an angle of $60^{\circ}$ with each other. From the resulting formula and the well-known expression for the mutual inductance of two parallel, straight filaments, the solution for the triangles can be built up. If $s$ denote the length of the side of the triangle, and $d$ the distance between the planes, the mutual inductance of the two equal, parallel, coaxial triangles is given by the exact formula:

$$
\begin{aligned}
M=0.006 s & {\left[\begin{array}{l}
\log \frac{s+\sqrt{s^{2}+d^{2}}}{d}-\log \frac{\sqrt{s^{2}+d^{2}}+\frac{s}{2}}{\sqrt{s^{2}+d^{2}}-\frac{s}{2}}-\frac{\sqrt{s^{2}+d^{2}}}{s}+\frac{d}{s} \\
+\frac{\mathrm{I}}{\sqrt{3}} \frac{d}{s}\{B+D-A-C\}
\end{array}\right] \quad \text { microhenries } }
\end{aligned}
$$


in which the angles $A, B, C$, and $D$ are completely defined, so far as concerns their combination, by the relations:

$A=\sin ^{-1} \frac{\sqrt{3}}{2} \frac{d^{2}+s\left(\frac{s}{2}+\sqrt{s^{2}+d^{2}}\right)}{\left(\frac{s}{2}+\sqrt{s^{2}+d^{2}}\right) \sqrt{d^{2}+\frac{3}{4} s^{2}}}$

which can also be written, fixing the quadrant of the angle,

$A=\cos ^{-1} \frac{\mathrm{I}}{2} \frac{d\left(\sqrt{s^{2}+d^{2}}-s\right)}{\left(\frac{s}{2}+\sqrt{s^{2}+d^{2}}\right) \sqrt{d^{2}+\frac{3}{4} s^{2}}} ;$

$B=\sin ^{-1} \frac{\sqrt{3}}{2} \frac{d^{2}+s\left(s+\sqrt{s^{2}+d^{2}}\right)}{\left(s+\sqrt{s^{2}+d^{2}}\right) \sqrt{d^{2}+\frac{3}{4} s^{2}}}=\cos ^{-1} \frac{1}{2} \frac{d}{\sqrt{d^{2}+\frac{3}{4} s^{2}}} ;$

$C=\sin ^{-1} \frac{\sqrt{3}}{2}=\cos ^{-1} \frac{I}{2}$

$D=\sin ^{-1} \frac{\sqrt{3}}{2} \frac{d}{\sqrt{s^{2}+d^{2}}-\frac{s}{2}}=\cos ^{-1} \frac{\left(-s+\frac{1}{2} \sqrt{s^{2}+d^{2}}\right)}{\left(-\frac{s}{2}+\sqrt{s^{2}+d^{2}}\right)}$.

The series expansion of formula (I0) in powers of $\frac{d}{s}$ is:

$$
\begin{aligned}
M & =0.006 s\left[\log \frac{s}{d}-\mathrm{I} .405465+\frac{d}{\delta}\left(\mathrm{I}+\frac{2 \pi}{3 \sqrt{3}}\right)\right. \\
& \left.-\frac{\mathrm{II}}{\mathrm{I} 2} \frac{d^{2}}{s^{2}}+\frac{2 \mathrm{O} 3}{864} \frac{d^{4}}{s^{4}}-\cdots\right] \quad \text { microhenries }
\end{aligned}
$$

and if the geometric and arithmetic mean distances be substituted in this last formula, as described in the preceding section, the inductance of a short triangular coil of length $b$ proves to be

$$
\begin{gathered}
L=0.006 s n^{2}\left[\log \frac{s}{b}+0.094535+0.73640 \frac{b}{s}-0.15277 \frac{b^{2}}{s^{2}}\right. \\
\left.+0.01566 \frac{b^{4}}{s^{4}}-\cdots\right] \text { microhenries. }
\end{gathered}
$$

6. HEXAGONAL COII.

To build up the solution for two equal, parallel, coaxial hexagons the same method was employed as for the triangles. The work is much more complicated, it is true, and the series expansion of this expression much more laborious. Using the same nomenclature as before, the resulting formula is. 


$$
\begin{aligned}
M=0.012 s[ & {\left[\log \frac{s+\sqrt{s^{2}+d^{2}}}{d}-\frac{\sqrt{s^{2}+d^{2}}}{s}+\frac{d}{s}+\frac{\sqrt{4 s^{2}+d^{2}}}{s}-\frac{\sqrt{3 s^{2}+d^{2}}}{s}\right.} \\
& -\log \frac{s+\sqrt{4 s^{2}+d^{2}}}{\sqrt{3 s^{2}+d^{2}}}-\log \frac{\sqrt{s^{2}+d^{2}}+\frac{s}{2}}{\sqrt{s^{2}+d^{2}}-\frac{s}{2}}+\log \frac{\sqrt{3 s^{2}+d^{2}}+\frac{3}{2} s}{\sqrt{3 s^{2}+d^{2}}-\frac{3}{2} s} \\
& -\log \frac{\sqrt{4 s^{2}+d^{2}}+s}{\sqrt{4 s^{2}+d^{2}}-s} \\
& +\frac{d}{s \sqrt{3}}\{A-B+C-D-E \\
& +F-G+H\}] \quad \text { microhenries }
\end{aligned}
$$

in which

$$
A=\sin ^{-1} \frac{\sqrt{3}}{2} \cdot \frac{d^{2}+s\left(\frac{3}{2} s+\sqrt{3 s^{2}+d^{2}}\right)}{\left(\sqrt{d^{2}+\frac{3}{4} s^{2}}\right)\left(\frac{3}{2} s+\sqrt{3 s^{2}+d^{2}}\right)}
$$

which can also be written, fixing the quadrant of the angle,

$$
A=\cos ^{-1}\left(-\frac{\mathrm{I}}{2}\right) \frac{d\left(3 s+\sqrt{3 s^{2}+d^{2}}\right)}{\left(\sqrt{d^{2}+\frac{3}{4} s^{2}}\right)\left(\frac{3}{2} s+\sqrt{3 s^{2}+d^{2}}\right)}
$$

$$
B=\sin ^{-1} \frac{\sqrt{3}}{2} \cdot \frac{d^{2}+s\left(s+\sqrt{s^{2}+d^{2}}\right)}{\left(\sqrt{d^{2}+\frac{3}{4} s^{2}}\right)\left(s+\sqrt{s^{2}+d^{2}}\right)}=\cos ^{-1}\left(-\frac{1}{2}\right) \frac{d}{\sqrt{d^{2}+\frac{3}{4} s^{2}}}
$$$$
C=\sin ^{-1} \frac{\sqrt{3}}{2}=\cos ^{-1}\left(-\frac{1}{2}\right)
$$$$
D=\sin ^{-1} \frac{d \frac{\sqrt{3}}{2}}{\left(\frac{s}{2}+\sqrt{s^{2}+d^{2}}\right)}=\cos ^{-1}\left(-\frac{1}{2}\right) \frac{2 s+\sqrt{s^{2}+d^{2}}}{\frac{s}{2}+\sqrt{s^{2}+d^{2}}}
$$$$
E=\sin ^{-1} \frac{\sqrt{3}}{2} \cdot \frac{d^{2}+2 s\left(s+\sqrt{4 s^{2}+d^{2}}\right)}{\sqrt{3 s^{2}+d^{2}}\left(s+\sqrt{4 s^{2}+d^{2}}\right)}
$$$$
E=\cos ^{-1} \frac{I}{2} \frac{d\left(\sqrt{4 s^{2}+d^{2}}-2 s\right)}{\sqrt{3 s^{2}+d^{2}}\left(s+\sqrt{4 s^{2}+d^{2}}\right)}
$$

$F=\sin ^{-1} \frac{\sqrt{3}}{2} \frac{d^{2}+2 s\left(\frac{3}{2} s+\sqrt{3 s^{2}+d^{2}}\right)}{\sqrt{3 s^{2}+d^{2}}\left(\frac{3}{2} s+\sqrt{3 s^{2}+d^{2}}\right)}$ 
which can also be written, fixing the quadrant of the angle,

$$
\begin{gathered}
F=\cos ^{-1} \frac{\mathrm{I}}{2} \frac{d \sqrt{3 s^{2}+d^{2}}}{\sqrt{3 s^{2}+d^{2}}\left(\frac{3}{2} s+\sqrt{3 s^{2}+d^{2}}\right)} \\
G=\sin ^{-1} \frac{\sqrt{3}}{2} \frac{d^{2}+s\left(\frac{s}{2}+\sqrt{s^{2}+d^{2}}\right)}{\sqrt{d^{2}+\frac{3}{4} s^{2}\left(\frac{s}{2}+\sqrt{s^{2}+d^{2}}\right)}}
\end{gathered}
$$

which can also be written, fixing the quadrant of the angle,

$$
\begin{gathered}
G=\cos ^{-1} \frac{\mathrm{I}}{2} \frac{d\left(-s+\sqrt{s^{2}+d^{2}}\right)}{\sqrt{d^{2}+\frac{3}{4} s^{2}\left(\frac{s}{2}+\sqrt{s^{2}+d^{2}}\right)}} \\
H=\sin ^{-1} \frac{\sqrt{3}}{2} \cdot \frac{d^{2}+s \sqrt{3 s^{2}+d^{2}}}{\sqrt{d^{2}+\frac{3}{4} s^{2}} \sqrt{3 s^{2}+d^{2}}}=\cos ^{-1} \frac{d\left(-\frac{3}{2} s+\frac{1}{2} \sqrt{3 s^{2}+d^{2}}\right)}{\sqrt{d^{2}+\frac{3}{4} s^{2}}\left(\sqrt{3 s^{2}+d^{2}}\right)}
\end{gathered}
$$

Expanding this in powers of $\frac{d}{s}$, we find, finally,

$$
\begin{gathered}
M=0.012 s\left[\log \frac{s}{d}-0.151524+\frac{d}{s}\left(1-\frac{\pi \sqrt{3}}{9}\right)+\frac{d^{2}}{s^{2}}\left(\frac{2 \sqrt{3}-3}{4}\right)\right. \\
\left.-\frac{d^{4}}{s^{4}}\left(\frac{33 \sqrt{3}-46}{216}\right)+\cdots\right] \\
\begin{array}{c}
M=0.012 s\left[\log \frac{s}{d}-0.151524+0.39540 \frac{d}{s}\right. \\
\left.+0.11603 \frac{d^{2}}{s^{2}}-0.05167 \frac{d^{4}}{s^{4}}+\cdots\right]
\end{array}
\end{gathered}
$$

so that for a short, hexagonal coil of length $b$,

$$
\begin{aligned}
& L=0.012 s n^{2}\left[\log \frac{s}{b}+1.348476+0.13180 \frac{b}{s}+0.01934 \frac{b^{2}}{s^{2}}\right. \\
& \left.-0.00344 \frac{b^{4}}{s^{4}}+\cdots\right] \quad \text { microhenries. }
\end{aligned}
$$

\section{Octagonal CoIL.}

For this the method is the same as for the two preceding cases. The formula for the mutual inductance of two, equal, parallel, coaxial octagons, derived from Marten's general formula, is: 


$$
\begin{aligned}
& M=0.016 s\left[\log \frac{s+\sqrt{s^{2}+d^{2}}}{d}-\log \frac{s+\sqrt{d^{2}+s^{2}(4+2 \sqrt{2})}}{\sqrt{d^{2}+s^{2}(3+2 \sqrt{2})}}-\frac{\sqrt{s^{2}+d^{2}}}{s}+\frac{d}{s}\right. \\
& +\frac{\sqrt{2}}{2} \log \frac{\frac{s}{2}(2+\sqrt{2})+\sqrt{d^{2}+s^{2}(2+\sqrt{2})}}{\sqrt{d^{2}+s^{2}(2+\sqrt{2})}-\frac{s}{2}(2+\sqrt{2})}-\frac{\sqrt{2}}{2} \log \frac{\sqrt{s^{2}+d^{2}}+\frac{\sqrt{2}}{2} s}{\sqrt{s^{2}+d^{2}}-\frac{\sqrt{2}}{2} s} \\
& -(I+\sqrt{2}) \log \frac{\sqrt{d^{2}+s^{2}(4+2 \sqrt{2})}+s}{\sqrt{d^{2}+s^{2}(4+2 \sqrt{2})-s}} \\
& +\frac{2+\sqrt{2}}{2} \log \frac{\sqrt{d^{2}+s^{2}(3+2 \sqrt{2})}+\frac{s}{2}(2+\sqrt{2})}{\sqrt{d^{2}+s^{2}(3+2 \sqrt{2})}-\frac{s}{2}(2+\sqrt{2})} \\
& -\frac{(2+\sqrt{2})}{2} \log \frac{\sqrt{d^{2}+s^{2}(2+\sqrt{2})}+\frac{\sqrt{2}}{2} s}{\sqrt{d^{2}+s^{2}(2+\sqrt{2})}-\frac{\sqrt{2}}{2} s}+\frac{\sqrt{d^{2}+s^{2}(4+2 \sqrt{2})}}{s} \\
& -\frac{\sqrt{d^{2}+s^{2}(3+2 \sqrt{2})}}{s}
\end{aligned}
$$$$
\left.+\frac{2 d}{\sqrt{2}}\{E-F+G-H-A+B-C+D\}\right] \text { microhenries }
$$

in which

$$
A=\sin ^{-1} \frac{d^{2} \frac{\sqrt{2}}{2}+(I+\sqrt{2}) s\left[s+\sqrt{d^{2}+s^{2}(4+2 \sqrt{2})}\right]}{\sqrt{d^{2}+s^{2}(3+2 \sqrt{2})}\left[s+\sqrt{d^{2}+s^{2}(4+2 \sqrt{2})}\right]}
$$

which can also be written, fixing the quadrant of the angle,

$$
\begin{gathered}
A=\cos ^{-1} \frac{d\left[-s+\frac{\sqrt{2}}{2} \sqrt{d^{2}+s^{2}(4+2 \sqrt{2})}\right]}{\sqrt{d^{2}+s^{2}(3+2 \sqrt{2})}\left[s+\sqrt{d^{2}+s^{2}(4+2 \sqrt{2})}\right]} \\
B=\sin ^{-1} \frac{d^{2} \frac{\sqrt{2}}{2}+(1+\sqrt{2}) s\left[\frac{s}{2}(2+\sqrt{2})+\sqrt{d^{2}+s^{2}(3+2 \sqrt{2})}\right]}{\sqrt{d^{2}+s^{2}(3+2 \sqrt{2})}\left[\frac{s}{2}(2+\sqrt{2})+\sqrt{d^{2}+s^{2}(3+2 \sqrt{2})}\right]}
\end{gathered}
$$


which can also be written. fixing the quadrant of the angle,

$$
\begin{gathered}
B=\cos ^{-1} \frac{\sqrt{2}}{2}\left[\frac{s}{2}(2+\sqrt{2})+\sqrt{d^{2}+s^{2}(3+2 \sqrt{2})}\right] \\
C=\sin ^{-1} \frac{\frac{d^{2} \sqrt{2}}{2}+\frac{s}{2}(2+\sqrt{2})\left[\frac{s \sqrt{2}}{2}+\sqrt{d^{2}+s^{2}(2+\sqrt{2})}\right]}{\sqrt{d^{2}+\frac{s^{2}}{2}(3+2 \sqrt{2})}\left[\frac{s \sqrt{2}}{2}+\sqrt{d^{2}+s^{2}(2+\sqrt{2})}\right]}
\end{gathered}
$$

which can also be written, fixing the quadrant of the angle,

$$
\begin{gathered}
C=\cos ^{-1} \frac{\sqrt{2}}{2} \frac{d\left[-s+\sqrt{d^{2}+s^{2}(2+\sqrt{2})}\right]}{\sqrt{d^{2}+\frac{s^{2}}{2}(3+2 \sqrt{2})\left[\frac{s \sqrt{2}}{2}+\sqrt{d^{2}+s^{2}(2+\sqrt{2})}\right]}} \\
D=\sin ^{-1} \frac{\frac{d^{2} \sqrt{2}}{2}+\frac{s}{2}(2+\sqrt{2}) \sqrt{d^{2}+s^{2}(3+2 \sqrt{2})}}{\sqrt{d^{2}+\frac{s^{2}}{2}(3+2 \sqrt{2})} \sqrt{d^{2}+s^{2}(3+2 \sqrt{2})}}
\end{gathered}
$$

which can also be written, fixing the quadrant of the angle,

$$
\begin{gathered}
D=\cos ^{-1} \frac{d}{2} \frac{\left[-s(2+\sqrt{2})+\sqrt{2} \sqrt{d^{2}+s^{2}(3+2 \sqrt{2})}\right]}{\sqrt{d^{2}+\frac{s^{2}}{2}(3+2 \sqrt{2})} \sqrt{d^{2}+s^{2}(3+2 \sqrt{2})}} \\
E=\sin ^{-1} \frac{\sqrt{2}}{2} \frac{d^{2}+s\left[\frac{s}{2}(2+\sqrt{2})+\sqrt{d^{2}+s^{2}(2+\sqrt{2})}\right]}{\sqrt{d^{2}+\frac{s^{2}}{2}\left[\frac{s}{2}(2+\sqrt{2})+\sqrt{d^{2}+s^{2}(2+\sqrt{2})}\right]}}
\end{gathered}
$$

which can also be written, fixing the quadrant of the angle,

$$
\begin{gathered}
E=\cos ^{-1} \frac{-\frac{d}{2}\left[s(2+\sqrt{2})+\sqrt{2} \sqrt{d^{2}+s^{2}(2+\sqrt{2})}\right]}{\sqrt{d^{2}+\frac{s^{2}}{2}\left[\frac{s}{2}(2+\sqrt{2})+\sqrt{d^{2}+s^{2}(2+\sqrt{2})}\right]}} \\
F=\sin ^{-1} \frac{\sqrt{2}}{2} \cdot \frac{d^{2}+s\left(s+\sqrt{s^{2}+d^{2}}\right)}{\sqrt{d^{2}+\frac{s^{2}}{2}}\left(s+\sqrt{s^{2}+d^{2}}\right)}=\cos ^{-1}\left(-\frac{\sqrt{2}}{2}\right) \frac{d}{\sqrt{d^{2}+\frac{s^{2}}{2}}} \\
G=\sin ^{-1} \frac{\sqrt{2}}{2}=\cos ^{-1}\left(-\frac{\sqrt{2}}{2}\right) \\
H=\sin ^{-1} \frac{d \frac{\sqrt{2}}{2}}{\frac{s}{2} \sqrt{2}+\sqrt{s^{2}+d^{2}}}=\cos ^{-1}\left[-s-\frac{\sqrt{2}}{2} \sqrt{s^{2}+d^{2}}\right]
\end{gathered}
$$


For the case that the octagons are near together, this gives the series:

$$
\begin{aligned}
M=0.016 s & {\left[\log \frac{s}{d}+0.211976+0.214602 \frac{d}{s}\right.} \\
& \left.\left.+0.105167 \frac{d^{2}}{s^{2}}-0.026487 \frac{d^{4}}{s^{4}}+\cdots\right] \text { microhenries, (I } 7\right)
\end{aligned}
$$

which gives, finally, for the short octagonal coil of length $b$ the formula:

$$
\begin{array}{rl}
L=0.016 & s n^{2}\left[\log \frac{s}{b}+1.7 \mathrm{II} 976+0.071534 \frac{b}{s}\right. \\
& \left.+0.017528 \frac{b^{2}}{s^{2}}-0.001766 \frac{b^{4}}{s^{4}}+\cdots\right] \text { microhenries. }
\end{array}
$$

\section{INDUCTANCE OF POLYGONS OF ROUND WIRE.}

As a by-product of the developments of the preceding sections should be given the formulas for the inductance of polygons of round wire. Such formulas have not been previously published, but they can be readily deduced from the mutual inductance formulas which have had to be derived in obtaining the formulas for the parallel polygons, and from the well-known formulas for single wires and parallel filaments. ${ }^{4}$ The inductance of the polygon follows from the usual methods of summation for a circuit of various elements in series. A check is afforded by substituting in formulas (10), (13), and (I6) for the mutual inductance of parallel equal polygons the geometric and arithmetic mean distances of the circular cross section. This method is not such a good approximation as the preceding, since it amounts to the integration over the circular cross section of the formula for equal filaments instead of the general formula, which is not available. The two methods agree entirely as to the logarithm and the constant term.

The formulas given below were obtained by the summation method. They are not strictly accurate, since the mutual inductance formulas used apply strictly only to filaments of negligible cross section, instead of to finite wires of radius $\rho$. However, the error is very small for the usual case where the dimensions of the cross section are small compared with the side of the polygon.

'B. S. Sci. Papers, No. I69, formulas 94 and 98, pp. 150-15r; 19r2. (B. S. Bulletin, 8, 150-15r.) 
Triangle:

$L=0.006 s\left[\log \frac{s+\sqrt{s^{2}+\rho^{2}}}{\rho}-\sqrt{1+\frac{\rho^{2}}{s^{2}}}-0.848612+\frac{\rho}{s}\right]$

$L=0.006 s\left[\log \frac{s}{\rho}-\mathrm{I} . \mathrm{I} 55465+\frac{\rho}{s}-\frac{\mathrm{I}}{4} \frac{\rho^{2}}{s^{2}}+\cdots\right]$ microhenries. (I 9)

Hexagon:

$$
\begin{aligned}
& L=0.012 s\left[\log \frac{s+\sqrt{s^{2}+\rho^{2}}}{\rho}-\sqrt{1+\frac{\rho^{2}}{s^{2}}}+0.405333+\frac{\rho}{s}\right] \\
& L=0.012 s\left[\log \frac{s}{\rho}+0.098476+\frac{\rho}{s}-\frac{1}{4} \frac{\rho^{2}}{s^{2}}+\cdots\right] \text { microhenries. (20) }
\end{aligned}
$$

Octagon:

$$
\begin{aligned}
& L=0.016 s\left[\log \frac{s+\sqrt{s^{2}+\rho^{2}}}{\rho}-\sqrt{I+\frac{\rho^{2}}{s^{2}}}+0.768829+\frac{\rho}{s}\right] \\
& L=0.016 s\left[\log \frac{s}{\rho}+0.461976+\frac{\rho}{s}-\frac{1}{4} \frac{\rho^{2}}{s^{2}}+\cdots\right] \text { microhenries. (2I) }
\end{aligned}
$$

\section{TABLES OF THE EQUIVALENT RADIUS OF POLYGONAL COILS.}

In the preparation of the tables of the equivalent radius to be used in the calculation of the inductance of polygonal coils, those dimensions which are adopted as fundamental are the axial length of the coil and the diameter of the circle circumscribed about the polygon. The axial length $b$ of the coil is taken as the distance between centers of adjacent turns (pitch) multiplied by the number of turns. This gives the length of the equivalent current sheet. The diameter of the circumscribed circle $2 r$ can readily be obtained by calipering over opposite vertices of the polygonal coil and then by subtracting the diameter of the wire. The rarer cases, where the polygon has an odd number of sides, can be treated with little greater difficulty.

Expressed in terms of these constants, the formulas (4), (12), (I5), and (18), already given for short, polygonal coils, become:

Short triangular coil:

$$
\begin{gathered}
L=0.006 n^{2} s\left[\log \frac{2 r}{b}-0.049307+0.85032\left(\frac{b}{2 r}\right)\right. \\
\left.-0.20369\left(\frac{b}{2 r}\right)^{2}+0.02784\left(\frac{b}{2 r}\right)^{4}-\cdots\right] \text { microhenries. }
\end{gathered}
$$


Short square coil:

$$
\begin{aligned}
& L=0.008 n^{2} s\left[\log \frac{2 r}{b}+0.37942+0.47 \text { I } 40\left(\frac{b}{2 r}\right)-0.014298\left(\frac{b}{2 r}\right)^{2}\right. \\
& \left.-0.02904\left(\frac{b}{2 r}\right)^{4}+0.02757\left(\frac{b}{2 r}\right)^{6}-0.04224\left(\frac{b}{2 r}\right)^{8}+\cdots\right] \\
& \quad \text { microhenries. }
\end{aligned}
$$

Short hexagonal coil:

$$
\begin{gathered}
L=0.012 n^{2} s\left[\log \frac{2 r}{b}+0.65533+0.26960\left(\frac{b}{2 r}\right)+0.07736\left(\frac{b}{2 r}\right)^{2}\right. \\
\left.-0.05504\left(\frac{b}{2 r}\right)^{4}+\cdots\right] \text { microhenries. }
\end{gathered}
$$

Short octagonal coil:

$$
\begin{gathered}
L=0.016 n^{2} s\left[\log \frac{2 r}{b}+0.75143+0.18693\left(\frac{b}{2 r}\right)\right. \\
\text { +0.11969 } \left.\left(\frac{b}{2 r}\right)^{2}-0.08234\left(\frac{b}{2 r}\right)^{4}+\cdots\right] \text { microhenries. }
\end{gathered}
$$

These give very accurate values of the inductance for coils as long as one-half the radius of the circumscribed circle, and may be used for somewhat longer coils with a very satisfactory degree of accuracy.

To calculate the equivalent radius of a given polygonal coil, the inductance is obtained from one of the foregoing formulas for the given value of $\frac{b}{2 r}$, and this is equated to the expression for the inductance of a circular solenoid (see formula (27)) in which everything is known except the equivalent radius and the factor $K$, which is a function of the ratio $\frac{2 a}{b}$ between the equivalent radius $a$ and the length of the coil. This quantity has been accurately and fully tabulated in Table $2 \mathrm{I}$ of B. S. Sci. Papers, No. 169. (B. S. Bulletin, 8, 224.) Assuming as a first approximation that the equivalent radius is that of the equal area circle $a_{0}$ the value of $K$ corresponding is taken from the table, and the inductance equation may then be solved to obtain a second approximation to the equivalent radius. A few repetitions of this process give a very accurate value of the equivalent radius. If certain values of the equivalent radius are already known for different values of the ratio $\frac{b}{2 r}$, a more accurate first approximation may be obtained in any further case, and the number of 
approximations very appreciably reduced. In most of the calculations for Table $\mathrm{I}$, three or four approximations sufficed.

The values of the equivalent radius of short coils given in Table I were obtained by this method, and also the values for the longer square coils. In Table $I$ are also given the values of the ratio $\frac{a}{a}$ between the actual equivalent radius and the radius of the

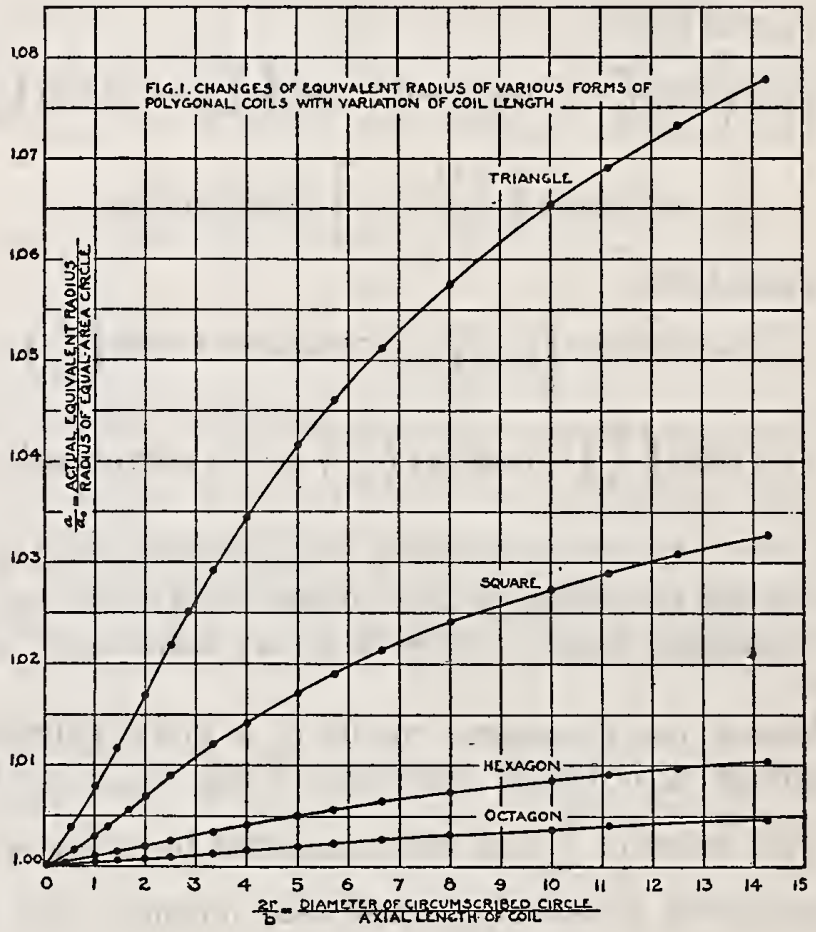

FIG. I.

equal area circle. A plot of these values as ordinates and $\frac{2 r}{b}$ as abscissas may be made to cover the region of long coils, since we know that, for any number of sides, the value of this ratio is unity for $\frac{2 r}{b}=0$. Figure I shows that, from such a plot, it is possible to interpolate values of this ratio for cases not covered by formulas (22) to (25). (This figure is given merely to indicate the form of the curves. Calculated values are shown by dots.)

By plotting the results in another way it is possible to obtain by interpolation the equivalent radius ratio $\frac{a}{a_{\circ}}$ for polygons for 
which formulas have not been derived. For this purpose it is best to choose values of $\frac{a}{a_{\circ}}$ as ordinates, and the reciprocal of the number of sides $\frac{\mathrm{I}}{N}$ as abscissas, each curve being drawn for a constant value of the ratio $\frac{b}{2 r}$. Advantage is taken of the fact that for an infinite number of sides, $\frac{I}{N}=0$, all the curves have the ordinate unity, whatever the value of the ratio $\frac{b}{2 r}$. Figure 2 gives an idea of the form of the curves. By proper choice of the scales accurate values may be interpolated, especially in the case of polygons of a large number of sides. The values tabulated for a twelve-sided polygon in Table $\mathrm{I}$ were thus obtained.

\section{CORRECTION FOR INSULATION SPACE.}

The values of the equivalent radius calculated by the preceding formulas and given in Table I apply strictly only for a polygonal current sheet; that is, only for a winding of infinitesimal thickness whose turns are separated one from the next by an insulating space of negligible width. For a single-layer winding of round wire the inductance has to be calculated by computing the correction for the insulation space in exactly the same manner as for a singlelayer circular coil. Thus the correction formula (80) and the constants in Tables 7 and 8 of B. S. Sci. Papers, No. 169 (B. S. Bulletin, 8, 197), are immediately applicable, if the equivalent radius of the polygonal coil be used in place of the radius $a$ in this formula. Usually this correction will be small and need not be taken into account except for precise work.

Exactly similar considerations apply for coils wound with wire other than circular, and for multilayer coils. The methods and formulas which have been developed for correcting for the actual distribution of the current in the cross section of a multilayer coil, as compared with a uniform distribution of current over the cross section in the case of a circular coil, is made by formula (93) of B.S.Sci. Papers, No.r69. To apply this to the multilayer polygonal coil, it is only necessary to find the equivalent radius of a circular coil corresponding to the polygon which passes through the center of the cross section. This is used for the mean radius $a$ in the formula. 


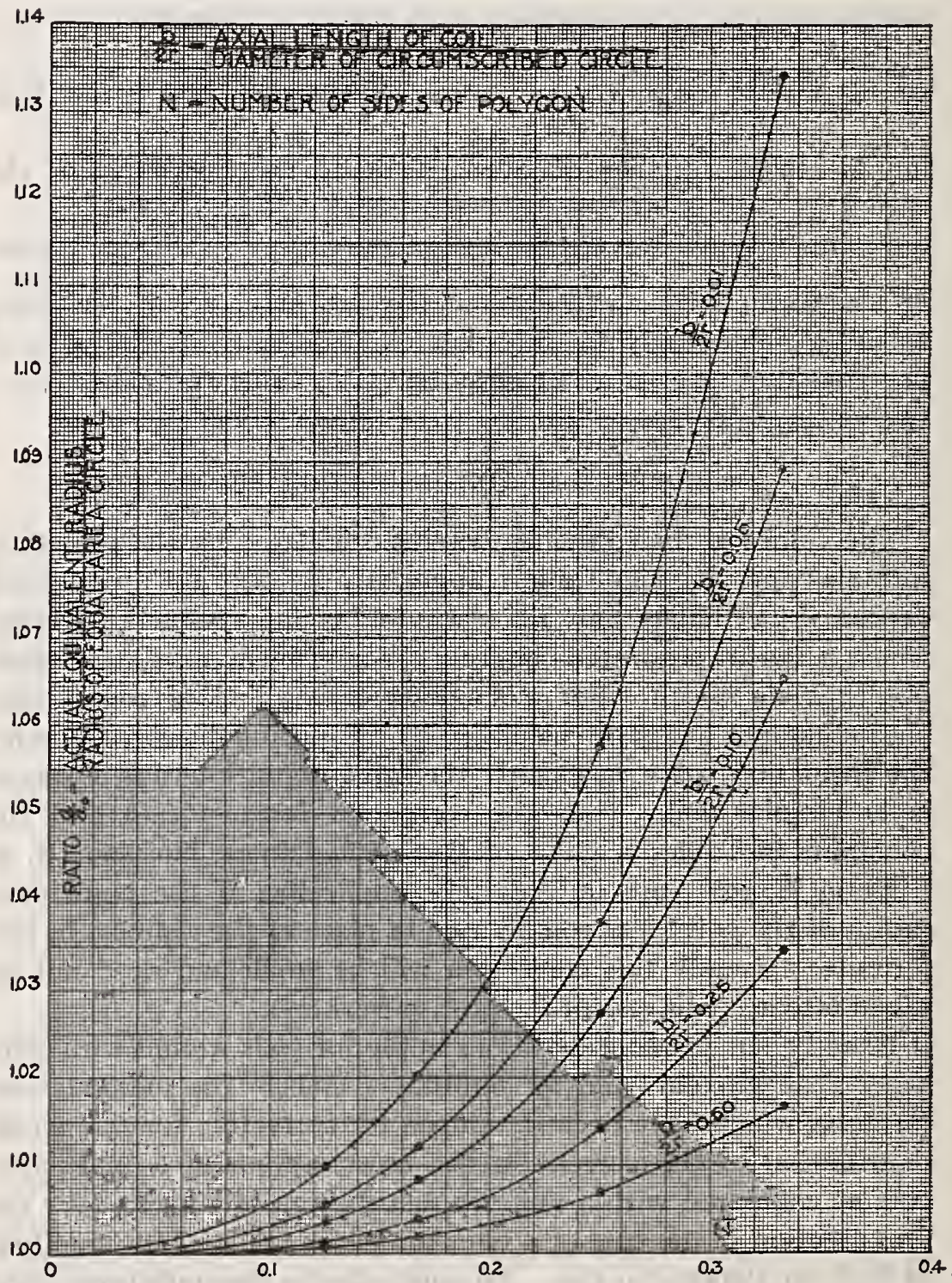

FIG. 2.-Variation of equivalent radius of polygonal coil with number of sides $(N)$ of polygon. 
In the next section are given the working formulas for polygonal coils, and Table I, from which the equivalent radius may be obtained. Examples are also given to illustrate the method of making numerical calculations.

\section{WORKING FORMULAS AND TABLE OF EQUIVALENT RADII.}

[All dimensions are in centimeters.]

Let

$N=$ number of sides of the polygon;

$r=$ radius of the circumscribed circle;

$s=$ length of side of the polygon;

$D_{1}=$ the pitch of the winding in the layer;

$D_{2}=$ the distance between centers of corresponding wires in successive layers;

$n=$ number of turns;

$n_{1}=$ number of turns in the layer;

$n_{2}=$ number of layers;

$d=$ diameter of the bare wire;

$b=$ axial length of the coil;

$c=$ radial thickness of the coil;

$a=$ equivalent radius of the coil;

$a_{\mathrm{o}}=$ radius of circle having same area as the polygon;

$a_{1}=$ radius of circle having the same perimeter as the polygon.

The following relations hold for any regular polygon:

$$
\begin{aligned}
\left(\frac{a_{0}}{r}\right)^{2} & =\frac{N}{2 \pi} \sin \frac{2 \pi}{N} \\
\frac{a_{1}}{r} & =\frac{N}{\pi} \sin \frac{\pi}{N} \\
2 r & =\frac{s}{\sin \frac{\pi}{N}}
\end{aligned}
$$

(a) SINGLE-LAYER POLYGONAL COII.

Usually the diameter of the circumscribed circle will be obtained by calipering over opposite vertices of the polygonal coil and subtracting the diameter of the wire. Sometimes the length of the side may be given or it may be easier to measure than $2 r$. In this case $2 r$ will be calculated from $s$ by equation (26).

The length of the equivalent polygonal current sheet is $b=n D_{1}$. With this the ratio $\frac{b}{2 a}$ can at once be found, and the equivalent radius $a$ of a cylindrical current sheet obtained for this value by interpolating in Table $\mathbf{I}$. 
The inductance of the equivalent cylindrical current sheet is then found by the formula:

$$
L_{s}=0.002 \pi^{2} n^{2} a\left(\frac{2 a}{b}\right) K \quad \text { microhenries, }
$$

in which $K$ is a function of the ratio $\frac{2 a}{b}$, and may be obtained from the Table 2 I, B. S. Sci. Papers, No. I69 (B. S. Bulletin, 8, 224).

To correct for the insulation space, calculate

$$
\Delta L=0.004 \pi n a(A+B) \text { microhenries, }
$$

the constants $A$ and $B$ being obtained from Tables VII and VIII of B. S. Sci. Papers, No. 169 , for the given number of turns and ratio $\frac{d}{D_{1}}$. The inductance of the single-layer coil is $L=L_{s}-\Delta L$. (b) MULTIPLE-LAYER POLYGONAL, COII.

The dimensions of the rectangular cross section of the equivalent circular coil with the current uniformly distributed over the cross section are $b=n_{1} D_{1}, c=n_{2} D_{2}$. The mean of the radii of the circles circumscribed around the polygons formed by the turns of the inner and the outer layers of the coil is to be taken as $r$, the radius of the circumscribed circle of the mean polygon. If the dimensions of the cross section are not too large, in comparison with $r$, the value of $a$ obtained from Table I for the given value of $\frac{b}{2 r}$ gives very accurately the mean radius of a circular coil of rectangular cross section having the same inductance, the current being uniformly distributed over the rectangular cross section. This inductance is given by either of the formulas:

$$
\begin{aligned}
& L_{u}=0.002 \pi^{2} n^{2} a\left(\frac{2 a}{b}\right)(K-k) \quad \text { microhenries } \\
& L_{u}=0.001 n^{2} a P^{\prime}
\end{aligned}
$$

in which the factor $K$ is the same as in formula (27), and tne quantities $P^{\prime}$ and $k$ are functions of $\frac{c}{2 a}$, and $\frac{b}{c}$ or $\frac{c}{b}$, and may be taken from the tables of B. S. Sci. Papers, No. 455 (18, p. 477). Formula (29) is more convenient for relatively long coils, while formula 30 is especially useful for short coils, unless $\frac{c}{2 a}$ is small. 
To correct for the insulation space, formula (93) of B. S. Sci. Papers, No. I69, should be used, if the pitches in the layer and between the layers are equal. If this is not so, sufficient accuracy is obtained by assuming equality of $D_{1}$ and $D_{2}$, and using the mean of their values. This correction is small. This value added to $L_{u}$ gives the inductance of the multilayer coil.

(c) EXAMPLES.

EXAMPLE I.-To calculate the inductance of an octagonal coil of 50 turns of round wire, $0.2 \mathrm{~cm}$ in diameter, with a pitch of $0.4 \mathrm{~cm}$. The mean of measurements taken with calipers over opposite vertices of the polygonal coil was II.24 cm. Thus the diameter of the circumscribed circle is $2 r=11.04 \mathrm{~cm}$.

The length of the equivalent current sheet is then $b=50 \times 0.4=$ $20 \mathrm{~cm}$ and accordingly $\frac{2 r}{b}=0.552$. Interpolating in Table $\mathrm{I}$ for this value of $\frac{2 r}{b}$, we find $\frac{a}{r}=0.949 \mathrm{I}$, which gives for the equivalent radius $a=0.949 \mathrm{I} \frac{(\mathrm{I} \mathrm{I} .04)}{2}=5.24 \mathrm{~cm}$.

The inductance of the polygonal current sheet is, accordingly, the same as that of a cylindrical current sheet having the same length, same number of turns, and a radius of $5.24 \mathrm{~cm}$. The ratio $\frac{2 a}{b}=\frac{10.48}{20}=0.524$. For this, Table 2I, B. S. Sci. Papers, No. 169, gives $K=0.8$ I08. Thus $L_{s}=0.002 \pi^{2}(50)^{2}(5.24)$ (0.524) (0.8108) $=$ rog.86 microhenries. For the correction we have $\frac{d}{D_{1}}=\frac{0.2}{0.4}=0.5$, and thus from Table $7, B$. S. Sci. Papers, No. 169, the value $A=-0.136$ is found. The value of $B$ from Table 8 , for $n=50$, is 0.319 . Thus $\Delta L=0.004 \pi$ (50) 5.24 (0.183) $=0.60$ microhenries. So that, finally, the inductance of the octagonal coil is 109.26 microhenries.

EXAMPLE 2.-The results of similar calculations, made for certain of the r2-sided, single-layer, standard coils of the Bureau of Standards, are given in the following tabulation. The nomenclature is the same as in the preceding example. In the last column are given the results of measurements on these coils. In general, the measured values are somewhat larger than the cal- 
culated values, but the differences are by no means regular. Undoubtedly difficulties in obtaining the dimensions are responsible for part of the difference, and for the smaller coils errors of measurement of the inductance are appreciable.

\begin{tabular}{|c|c|c|c|c|c|c|c|c|c|c|c|}
\hline Coil. & $n$ & $b$ & $d$ & $D_{1}$ & $r$ & $\frac{b}{2 r}$ & $a$ & $K$ & $L_{n}$ & $L$ (calc.) & $L$ (obs.) \\
\hline 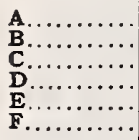 & $\begin{array}{r}23 \\
28 \\
52 \\
34 \\
62 \\
117\end{array}$ & $\begin{array}{r}7.3 \\
9.0 \\
11.0 \\
10.8 \\
13.1 \\
18.5\end{array}$ & $\begin{array}{l}0.12 \\
.15 \\
.12 \\
.15 \\
.12 \\
.05\end{array}$ & $\begin{array}{l}0.32 \\
.32 \\
.212 \\
.318 \\
.211 \\
.158\end{array}$ & $\begin{array}{r}6.35 \\
8.25 \\
11.43 \\
11.43 \\
13.97 \\
19.05\end{array}$ & $\begin{array}{l}0.575 \\
.546 \\
.481 \\
.472 \\
.469 \\
.486\end{array}$ & \begin{tabular}{r|}
6.21 \\
8.07 \\
11.17 \\
11.17 \\
13.66 \\
18.62
\end{tabular} & $\begin{array}{r}0.5650 \\
.5522 \\
.5219 \\
.5173 \\
.5154 \\
.5239\end{array}$ & $\begin{array}{r}62.2 \\
123.5 \\
632.2 \\
272.9 \\
1113.2 \\
5316.6\end{array}$ & $\begin{array}{r}62.4 \\
123.2 \\
630.0 \\
272.3 \\
1109.8 \\
5323\end{array}$ & $\begin{array}{r}61.7 \\
126.3 \\
630.5 \\
274.6 \\
1115.5 \\
5387\end{array}$ \\
\hline
\end{tabular}

NotE. -The values of $L_{\mathrm{B}}, L$ (calculated), and $L$ (observed) are all in microhenries.

EXAMPLE 3.-Suppose a square coil, wound in ro layers of ro turns each, the turn at the center of the cross section forming a square 4 feet on a side. The wire is supposed to have a bare diameter of $\mathrm{I} \mathrm{mm}$, and the pitch, both in the layer and between the layers, is $5 \mathrm{~mm}$. Thus the cross section of an equivalent coil, having a uniform current distribution over the cross section, would have the dimensions $b=c=5 \mathrm{~cm}$.

The diameter of the circle circumscribed about the mean turn is $2 r=\frac{4(30.48)}{\sin \frac{\pi}{4}}=4 \sqrt{2}(30.48)=172.4 \mathrm{~cm}$. Thus $\frac{b}{2 r}=\frac{5}{172.4}=0.0290$. Table I gives, for a square coil having this value of $\frac{b}{2 r}$, the value $\frac{a}{r}=0.834 \mathrm{I}$, so that the mean radius of the circular coil of rectangular cross section, having the same dimensions of cross section, the same number of turns, and the same inductance, assuming the current to be uniformly distributed over the cross section, is $a=0.834 \mathrm{I}(86.2)=7 \mathrm{I} .9 \mathrm{~cm}$.

For this case formula (29) is the more favorable. We have. $\frac{b}{c}=\mathrm{I}$ and $\frac{c}{2 a}=\frac{5}{\mathrm{I} 43.8}=0.03477=\frac{b}{2 a}$, so that $\frac{2 a}{b}=28.76$. Interpolating in Tables I and 2 of B.S.Sci. Papers No. 455, we find $k=0.01554$ and $K=0.09400$, so that from formula (29),

$$
L_{s}=0.002 \pi^{2}(\mathrm{IOO})^{2} 71.9(28.76) \quad 0.07846=32,026 \text { microhenries. }
$$

By graphical interpolation from the data of Table I, B. S. Sci. Papers, No. $455, P^{\prime}$ is found to be about $44.5^{8}$, which, sub- 
stituted in formula (30), gives $L_{s}=32,050$ microhenries. This is not so accurate as the preceding value but is useful as a check.

For calculating the correction for the insulation space we have $\log _{e} \frac{D}{d}=1.609$ and from page 141, B. S. Sci. Papers, No. 169, $E=0.017$. Substituting in formula (93) on page I40, same reference, $\Delta L=0.004 \pi(7 \mathrm{I} .9) 100(1.764)=159$ microhenries. Thus the inductance of the square coil is $L=32,026+159=32,185$ microhenries.

\section{(d) TABLE OF EQUIVALENT RADIUS.}

TABLE 1.-Constants for Obtaining the Equivalent Radius of Polygonal Coils.

\begin{tabular}{|c|c|c|c|c|c|c|c|}
\hline \multicolumn{4}{|c|}{ Trlangular coll. } & \multicolumn{4}{|c|}{ Square coil. } \\
\hline$\frac{b}{2 r}$ & $\frac{a}{a_{0}}$ & $\frac{a}{r}$ & $\log 10 \frac{a}{r}$ & $\frac{b}{2 r}$ & $\frac{a}{a_{0}}$ & $\frac{a}{r}$ & $\log 10 \frac{a}{r}$ \\
\hline 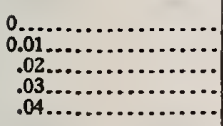 & $\begin{array}{l}1.2861 \\
1.1341 \\
1.1168 \\
1.1052 \\
1.0964\end{array}$ & $\begin{array}{l}0.8270 \\
0.7294 \\
.7181 \\
.7107 \\
.7050\end{array}$ & $\begin{array}{r}\text { I. } 91750 \\
.86299 \\
.85620 \\
.85169 \\
.84820\end{array}$ & $\begin{array}{r}0 \\
0.01 \ldots \ldots \\
.02 \ldots \ldots \\
.03 \ldots \ldots \ldots \\
.04 \ldots \ldots \\
\end{array}$ & $\begin{array}{l}1.1284 \\
1.0578 \\
1.0500 \\
1.0449 \\
1.0410\end{array}$ & $\begin{array}{l}0.9003 \\
.8440 \\
.8378 \\
.8337 \\
.8306\end{array}$ & $\begin{array}{l}\text { I. } 95440 \\
.92636 \\
.92315 \\
.92101 \\
.91937\end{array}$ \\
\hline 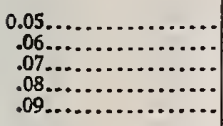 & $\begin{array}{l}1.0892 \\
1.0831 \\
1.0779 \\
1.0732 \\
1.0691\end{array}$ & $\begin{array}{l}0.7004 \\
.6965 \\
.6931 \\
.6901 \\
.6875\end{array}$ & $\begin{array}{r}1.84534 \\
.84291 \\
.84080 \\
.83893 \\
.83726\end{array}$ & $\begin{array}{r}0.05 \ldots \ldots \ldots \\
.06 \ldots \ldots \ldots \\
.07 \ldots \ldots \ldots \\
.08 \ldots \ldots \ldots \ldots \\
.09 \ldots \ldots \ldots \\
\end{array}$ & $\begin{array}{l}1.0378 \\
1.0351 \\
1.0328 \\
1.0308 \\
1.0290\end{array}$ & $\begin{array}{l}0.8280 \\
.8259 \\
.8241 \\
.8224 \\
.82105\end{array}$ & $\begin{array}{l}\text { I. } 91805 \\
.91693 \\
.91597 \\
.91512 \\
.91437\end{array}$ \\
\hline $\begin{array}{l}0.10 \ldots \ldots \\
.125 \ldots \ldots \\
.15 \ldots \ldots \\
.175 \ldots \ldots \ldots\end{array}$ & $\begin{array}{l}1.0654 \\
1.0576 \\
1.0512 \\
1.0460 \\
1.0416\end{array}$ & $\begin{array}{l}0.6851 \\
.6801 \\
.6760 \\
.6726 \\
.6698\end{array}$ & $\begin{array}{r}\text { I. } 83575 \\
.83254 \\
.82993 \\
.82776 \\
.82592\end{array}$ & $\begin{array}{r}0.10 \ldots \ldots \\
.125 \ldots \ldots \\
.15 \ldots \ldots \\
.175 \ldots \ldots \\
.20 \ldots \ldots\end{array}$ & $\begin{array}{l}1.0274 \\
1.0241 \\
1.0214 \\
1.0191 \\
1.0173\end{array}$ & $\begin{array}{l}0.8198 \\
.8171 \\
.8149 \\
.81315 \\
.8117\end{array}$ & $\begin{array}{r}\text { I. } 91370 \\
.91227 \\
.91112 \\
.91017 \\
.90938\end{array}$ \\
\hline $\begin{array}{r}0.25 \ldots \ldots \ldots \\
.30 \ldots \ldots \ldots \\
.35 \ldots \ldots \ldots \\
.40 \ldots \ldots \ldots \\
.45 \ldots \ldots\end{array}$ & $\begin{array}{l}1.0345 \\
1.0292 \\
1.0251 \\
1.0219 \\
1.0191\end{array}$ & $\begin{array}{l}0.6652 \\
.6618 \\
.65915 \\
.6571 \\
.6553\end{array}$ & $\begin{array}{l}\text { I. } 82298 \\
.82075 \\
.81899 \\
.81764 \\
.81645\end{array}$ & $\begin{array}{r}0.25 \ldots \ldots \ldots \\
.30 \ldots \ldots \\
.35 \ldots \ldots \\
.40 \ldots \ldots \ldots \\
.45 \ldots \ldots \ldots \\
\end{array}$ & $\begin{array}{l}1.0143 \\
1.0121 \\
1.0104 \\
1.0090 \\
1.0079\end{array}$ & $\begin{array}{l}0.8093 \\
.8075 \\
.8062 \\
.8051 \\
.8042\end{array}$ & $\begin{array}{r}\text { I. } 90811 \\
.90716 \\
.90642 \\
.90584 \\
.90536\end{array}$ \\
\hline $\begin{array}{r}0.50 \ldots \ldots \ldots \\
.6 \\
.7 \ldots \ldots \\
9 \ldots \ldots\end{array}$ & $\begin{array}{l}1.0169 \\
1.0139 \\
1.0118 \\
1.0103 \\
1.0090\end{array}$ & $\begin{array}{l}0.6539 \\
.6520 \\
.6506 \\
.6497 \\
.6488\end{array}$ & $\begin{array}{r}J .81551 \\
.81423 \\
.81333 \\
.81269 \\
.81213\end{array}$ & $\begin{array}{r}0.50 \ldots \ldots \\
.6 \\
.7 \\
.8 \\
.9 \\
9\end{array}$ & $\begin{array}{l}1.0070 \\
1.0056 \\
1.0046 \\
1.0039 \\
1.0034\end{array}$ & $\begin{array}{l}0.8035 \\
.80235 \\
.80155 \\
.8008 \\
.8006\end{array}$ & $\begin{array}{r}\text { I. } 90497 \\
.90436 \\
.90393 \\
.90353 \\
.90341\end{array}$ \\
\hline $1.0 \ldots$. & 1.0080 & 0.6482 & I. 81170 & $1.0 \ldots \ldots \ldots$ & 1.0030 & 0.8003 & I. 90324 \\
\hline$\frac{2 r}{b}$ & & & & $\frac{2 r}{b}$ & & & \\
\hline $\begin{array}{r}0.9 \ldots \ldots \ldots \ldots \ldots \\
.8 \ldots \ldots \ldots \ldots \\
.7 \ldots \ldots \ldots\end{array}$ & $\begin{array}{l}1.0072 \\
1.0064 \\
1.0056 \\
1.0048 \\
1.0040\end{array}$ & $\begin{array}{l}0.6477 \\
.6472 \\
.6466 \\
.6461 \\
.6456\end{array}$ & $\begin{array}{r}\mathrm{I} .81136 \\
.81101 \\
.81067 \\
.81032 \\
.80997\end{array}$ & $\begin{array}{r}0.9 \ldots \ldots . . \\
.8 \ldots \ldots \ldots \\
.7 \ldots \ldots \ldots \\
.6 \ldots \ldots \ldots \\
.5 \ldots \ldots \ldots\end{array}$ & $\begin{array}{l}1.0026 \\
1.00225 \\
1.0019 \\
1.0016 \\
1.0013\end{array}$ & $\begin{array}{l}0.8000 \\
.7997 \\
.7994 \\
.7992 \\
.7989\end{array}$ & $\begin{array}{r}\text { I. } 90307 \\
.90292 \\
.90278 \\
.90263 \\
.90250\end{array}$ \\
\hline $\begin{array}{l}0.4 \ldots \ldots \ldots \\
.3 \ldots \ldots \ldots \ldots \\
.2 \ldots \ldots \ldots \ldots \\
0.1 \ldots \ldots \ldots \ldots\end{array}$ & $\begin{array}{l}1.0032 \\
1.0024 \\
1.0016 \\
1.0008 \\
1.0000\end{array}$ & $\begin{array}{r}0.6451 \\
.6446 \\
.6440 \\
.6435 \\
0.6430\end{array}$ & $\begin{array}{r}\text { I. } .80963 \\
.80928 \\
.80893 \\
.80859 \\
\text { I. } 80824\end{array}$ & $\begin{array}{r}0.4 \ldots \ldots \\
.3 \ldots \ldots \\
.2 \ldots \ldots \\
0.0 \ldots \ldots\end{array}$ & $\begin{array}{l}1.0010 \\
1.0007 \\
1.0004 \\
1.0002 \\
1.0000\end{array}$ & $\begin{array}{r}0.7987 \\
.7984 \\
.7982 \\
.7980 \\
0.7979\end{array}$ & $\begin{array}{r}\text { I. } 90237 \\
.90225 \\
.90214 \\
.90203 \\
\text { I. } 90194\end{array}$ \\
\hline
\end{tabular}


TABLE 1.-Constants for Obtaining the Equivalent Radius of Polygonal Coils-Con.

\begin{tabular}{|c|c|c|c|c|c|c|c|}
\hline \multicolumn{4}{|c|}{ Hexagonal coll. } & \multicolumn{4}{|c|}{ Octagonal coll. } \\
\hline$\frac{b}{2 r}$ & $\frac{a}{a_{0}}$ & $\frac{a}{r}$ & $\log _{10} \frac{a}{r}$ & $\frac{b}{2 r}$ & $\frac{a}{a_{0}}$ & $\frac{a}{r}$ & $\log _{10} \frac{a}{r}$ \\
\hline $\begin{array}{r}0 \\
0.01 \\
.02 \ldots \ldots \\
.03 \ldots \ldots \\
.04 \ldots \ldots \\
.04 \ldots\end{array}$ & $\begin{array}{l}1.0501 \\
1.0203 \\
1.01715 \\
1.0151 \\
1.0136\end{array}$ & $\begin{array}{l}0.9549 \\
.92785 \\
.9250 \\
.9231 \\
.9218\end{array}$ & $\begin{array}{r}1.97997 \\
.96748 \\
.96614 \\
.96526 \\
.06462\end{array}$ & $\begin{array}{r}0 \\
0.01 \\
.02 \ldots \ldots \\
.03 \ldots \ldots \\
.04 \ldots \ldots\end{array}$ & $\begin{array}{l}1.0270 \\
1.0100 \\
1.0082 \\
1.0071 \\
1.0063\end{array}$ & $\begin{array}{l}0.9745 \\
.9583 \\
.95665 \\
.9556 \\
.9548\end{array}$ & $\begin{array}{r}\text { I. } 98878 \\
.98151 \\
.98075 \\
.98027 \\
.97992\end{array}$ \\
\hline 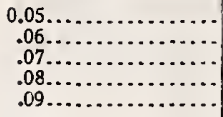 & $\begin{array}{l}1.01235 \\
1.0113 \\
1.0104 \\
1.00975 \\
1.00905\end{array}$ & $\begin{array}{l}0.9206 \\
.9197 \\
.91885 \\
.9183 \\
.9176\end{array}$ & $\begin{array}{r}1.96408 \\
.96363 \\
.96324 \\
.96296 \\
.96265\end{array}$ & $\begin{array}{r}0.05 \ldots \\
.06 \\
.07 \ldots \ldots \ldots \\
.08 \\
.09 \ldots \ldots \ldots \\
\end{array}$ & $\begin{array}{l}1.0056 \\
1.0051 \\
1.00465 \\
1.0043 \\
1.0010\end{array}$ & $\begin{array}{l}0.9542 \\
.9537 \\
.9533 \\
.9529 \\
.9526\end{array}$ & $\begin{array}{l}1.97964 \\
.97941 \\
.97921 \\
.97906 \\
.97892\end{array}$ \\
\hline 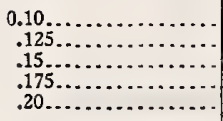 & $\begin{array}{l}1.0085 \\
1.0073 \\
1.0064 \\
1.0056 \\
1.0050\end{array}$ & $\begin{array}{l}0.9171 \\
.9160 \\
.9152 \\
.91 .45 \\
.9139\end{array}$ & $\begin{array}{l}\text { J. } 96243 \\
.96191 \\
.96151 \\
.96118 \\
.96092\end{array}$ & $\begin{array}{r}0.10 \ldots \ldots \\
.125 \ldots \ldots \\
.15 \ldots \ldots \\
.175 \ldots \ldots \\
.20 \ldots \ldots\end{array}$ & $\begin{array}{l}1.0037 \\
1.0031 \\
1.00265 \\
1.0023 \\
1.0020\end{array}$ & $\begin{array}{l}0.9523 \\
.9518 \\
.9514 \\
.9510 \\
.9508\end{array}$ & $\begin{array}{l}1.97879 \\
.97854 \\
.97835 \\
.97820 \\
.97808\end{array}$ \\
\hline 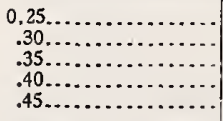 & $\begin{array}{l}1.0040 \\
1.0034 \\
1.00285 \\
1.0025 \\
1.0022\end{array}$ & $\begin{array}{l}0.9131 \\
.91245 \\
.9120 \\
.9117 \\
.9114\end{array}$ & $\begin{array}{r}1.96051 \\
.96021 \\
.95999 \\
.95984 \\
.95970\end{array}$ & $\begin{array}{r}0.25 \ldots \ldots \ldots \\
.30 \\
.35 \ldots \ldots \ldots \\
.40 \ldots \ldots \\
.45 \ldots \ldots \ldots \\
\end{array}$ & $\begin{array}{l}1.0016 \\
1.0013 \\
1.0011 \\
1.0009 \\
1.0008\end{array}$ & $\begin{array}{l}0.9504 \\
.9501 \\
.9499 \\
.9497 \\
.9496\end{array}$ & $\begin{array}{r}\text { I. } 97790 \\
.97777 \\
.97768 \\
.97759 \\
.97754\end{array}$ \\
\hline 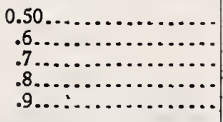 & $\begin{array}{l}1.0020 \\
1.00165 \\
1.0014 \\
1.00125 \\
1.0011\end{array}$ & $\begin{array}{l}0.9112 \\
.9109 \\
.9107 \\
.9105 \\
.9104\end{array}$ & $\begin{array}{r}1.95962 \\
.95947 \\
.95936 \\
.95929 \\
.95923\end{array}$ & 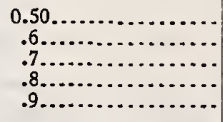 & $\begin{array}{l}1.0008 \\
1.00065 \\
1.00055 \\
1.00045 \\
1.0004\end{array}$ & $\begin{array}{l}0.9496 \\
.9495 \\
.9494 \\
.9493 \\
.9492\end{array}$ & $\begin{array}{r}1.97752 \\
.97748 \\
.97744 \\
.97739 \\
.97737\end{array}$ \\
\hline$\frac{2 r}{b}$ & & & & $\frac{2 r}{b}$ & & & \\
\hline 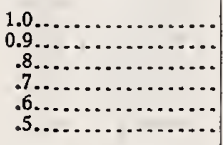 & $\begin{array}{l}1.0010 \\
1.0009 \\
1.0008 \\
1.0007 \\
1.0006 \\
1.0005\end{array}$ & $\begin{array}{l}0.9103 \\
.9102 \\
.9101 \\
.9100 \\
.9099 \\
.90985\end{array}$ & $\begin{array}{r}1.95918 \\
.95914 \\
.95910 \\
.95906 \\
.95901 \\
.95897\end{array}$ & 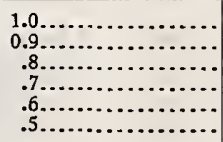 & $\begin{array}{l}1.0004 \\
1.00035 \\
1.0003 \\
1.0003 \\
1.00025 \\
1.0002\end{array}$ & $\begin{array}{l}0.9492 \\
.9492 \\
.9491 \\
.9491 \\
.9491 \\
.9490\end{array}$ & $\begin{array}{r}1.97735 \\
.97735 \\
.97733 \\
.97733 \\
.97731 \\
.97728\end{array}$ \\
\hline 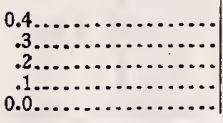 & $\begin{array}{l}1.0004 \\
1.0003 \\
1.0002 \\
1.0001 \\
1.0000\end{array}$ & $\begin{array}{r}0.9098 \\
.9097 \\
.9096 \\
.9095 \\
0.9094\end{array}$ & $\begin{array}{r}1.95892 \\
.95887 \\
.95884 \\
.95879 \\
1.95875\end{array}$ & 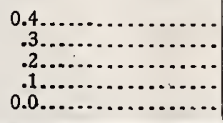 & $\begin{array}{l}1.00015 \\
1.0001 \\
1.0001 \\
1.00005 \\
1.0000\end{array}$ & $\begin{array}{l}0.9490 \\
.9489 \\
.9489 \\
.9489 \\
0.94885\end{array}$ & $\begin{array}{r}1.97726 \\
.97724 \\
.97724 \\
.97724 \\
1.97722\end{array}$ \\
\hline \multicolumn{4}{|c|}{ Twelve-sided coll. } & \multicolumn{4}{|c|}{ Twelve-sided coil. } \\
\hline$\frac{b}{2 r}$ & $\frac{a}{a_{0}}$ & $\frac{a}{r}$ & $\log 10 \frac{a}{r}$ & $\frac{b}{2 r}$ & $\frac{a}{a_{0}}$ & $\frac{a}{r}$ & $\log _{10} \frac{a}{r}$ \\
\hline 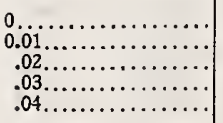 & $\begin{array}{l}1.0117 \\
1.0039 \\
1.00335 \\
1.0029 \\
1.0025\end{array}$ & $\begin{array}{l}0.9886 \\
.9810 \\
.9805 \\
.9800 \\
.97965\end{array}$ & $\begin{array}{r}1.99503 \\
.99168 \\
.99144 \\
.99124 \\
.99107\end{array}$ & 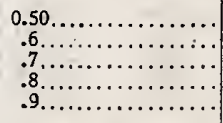 & $\begin{array}{l}1.0002 \\
1.00015 \\
1.00015 \\
1.0001 \\
1.0001\end{array}$ & $\begin{array}{l}0.9774 \\
.97735 \\
.97735 \\
.9773 \\
.9773\end{array}$ & $\begin{array}{r}1.99007 \\
.99005 \\
.99005 \\
.99003 \\
.99003\end{array}$ \\
\hline 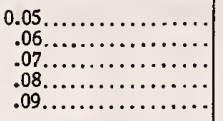 & $\begin{array}{l}1.0022 \\
1.00195 \\
1.0017 \\
1.0015 \\
1.00135\end{array}$ & $\begin{array}{l}0.9794 \\
.9791 \\
.9789 \\
.9787 \\
.9785\end{array}$ & $\begin{array}{r}1.99094 \\
.99083 \\
.99072 \\
.99064 \\
.99057\end{array}$ & $\frac{2 r}{b}$ & & & \\
\hline $\begin{array}{r}0.10 \ldots \ldots \ldots \ldots \ldots \ldots \\
.125 \ldots \ldots \ldots \ldots \ldots \ldots \ldots\end{array}$ & $\begin{array}{l}1.0012 \\
1.0010\end{array}$ & $\begin{array}{r}0.9784 \\
.9782\end{array}$ & $\begin{array}{r}1.99051 \\
.99042\end{array}$ & $1.0 \ldots \ldots$ & 1.0001 & 0.9773 & 1. 99003 \\
\hline $\begin{array}{l}.15 \ldots \ldots \ldots \ldots \\
.175 \ldots \ldots \ldots \ldots \ldots \\
.20 \ldots \ldots \ldots \ldots\end{array}$ & $\begin{array}{l}1.0008 \\
1.0007 \\
1.0006\end{array}$ & $\begin{array}{l}.9780 \\
.9779 \\
.9778\end{array}$ & $\begin{array}{l}.99033 \\
.99029 \\
.99024\end{array}$ & $\begin{array}{l}0.5 \ldots \ldots \ldots \\
0.0 \ldots \ldots \ldots\end{array}$ & $\begin{array}{l}1.00005 \\
1.0000\end{array}$ & $\begin{array}{l}0.97725 \\
.9772\end{array}$ & $\begin{array}{l}7.99001 \\
1.98999\end{array}$ \\
\hline 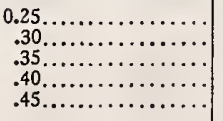 & $\begin{array}{l}1.0005 \\
1.0004 \\
1.00035 \\
1.0003 \\
1.00025\end{array}$ & $\begin{array}{l}0.9777 \\
.9776 \\
.97755 \\
.9775 \\
.97745\end{array}$ & $\begin{array}{r}1.99020 \\
.99016 \\
.99014 \\
.99012 \\
.99010\end{array}$ & . & & & \\
\hline
\end{tabular}

Washington, August Io, 1922. 